\title{
Role of parents as a protective factor against adolescent athletes' doping susceptibility
}

\author{
C Blank, ${ }^{1} \mathrm{PhD} ;$ V Leichtfried, ${ }^{1} \mathrm{PhD}$; D Müller, ${ }^{2} \mathrm{PhD}$; W Schobersberger, ${ }^{1} \mathrm{MD}$ \\ ${ }^{1}$ Institute for Sports Medicine, Alpine Medicine \& Health Tourism, University for Health Sciences, Medical Informatics and Technology, Hall; and Tirol Kliniken, \\ Innsbruck, Austria \\ ${ }^{2}$ National Anti-Doping Agency, Vienna, Austria
}

Corresponding author: C Blank (cornelia.blank@umit.at)

\begin{abstract}
Background. Although literature on sports psychology outlines parental influence in various areas, research has not focused on its potential in the framework of doping.

Objective. To assess whether parents' knowledge about doping effects, and their behaviour and beliefs might act as a protecting factor for Austrian junior (14 - 18 years) elite athletes' doping susceptibility (DS).

Methods. Questionnaires were distributed to 1818 student athletes and their parents. As well as collecting sociodemographic data, information about current sports activity levels and the former sports careers of parents, the following categories were included: $(i)$ knowledge about effects of doping; (ii) parental behaviour; (iii) parental beliefs about athletes' skills to become a professional athlete; and (iv) DS.

Results. In total 527 data sets were entered for analysis. Current state of knowledge was significantly different between mothers $(0.72(0.2))$ and fathers $(0.76(0.2))(p=0.003)$. Next to situational variables, only fathers' behaviour, which was moderated by fathers' beliefs, was a significant predictor of athletes' DS.

Conclusion. Fathers have the potential of acting as a protective factor for DS in athletes, but only if their level of belief is moderate. Doping prevention strategies should include parents, but need to be careful on the role they are planning to fulfil, with an emphasis on soft skills (e.g. communication). Future research might include variables from sports psychology such as motivational climate, goal orientation and belief in success as possible mediators of the influence of parents on their adolescent children in the sport setting.
\end{abstract}

S Afr J Sports Med 2015;27(3):87-91. DOI:10.7196/SAJSM.8094

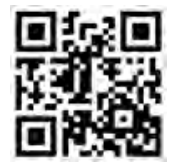

Doping in sport, as defined by the World Anti-Doping Code ${ }^{[1]}$ is generally considered as unhealthy, unethical, unsportsmanlike, and 'poor' behaviour in sport. Yet the abuse of performance-enhancing substances (PES) is not only an issue in adult elite sport but has also been reported in adolescent athletes. ${ }^{[2]}$ In the last decade doping prevention (including in adolescent athletes) has mostly been athlete-centred and education focused. ${ }^{[3]}$ Increasingly, research has been developed which focuses on athletes' support personnel such as trainers ${ }^{[4]}$ and physicians. ${ }^{[5]}$

Research in sports psychology supports the notion that variables in younger athletes (e.g. motivational climate, self-efficacy beliefs, goal orientation) might also be affected by their personal network including parents. ${ }^{[6,7]}$ LaVoi and Babkes Stellino ${ }^{[6]}$ found that the sports climate created by the parents, in terms of 'learning climate, 'worry conducive climate' and 'success without effort climate' significantly predicted athletes' good and poor behaviour in sport. Generally, several researchers have identified parents as 'sport socialisation agents, ${ }^{[8,9]}$ and they have the potential to act as role-models.

Different forms of parents' influence on their children's sport development have been analysed (e.g. expectations, values, encouragement, support and beliefs about their children's ability). ${ }^{[8]}$ In addition, White et al. ${ }^{[7]}$ report that effective parental beliefs and how their children perceive them have an influence on their development. It seems that perceived parental beliefs are related to goal orientation and personal beliefs in a coherent fashion. ${ }^{[7]}$

In the non-sport context parents are also increasingly recognised as part of prevention programmes (e.g. sexually transmitted diseases). ${ }^{[10]}$ The authors found that greater amounts of parent-child sexual communication are associated with fewer sexual risk behaviours, more condom use and greater intention of safer sex behaviour in the future.

Evidently, parents are involved in their children's development of general beliefs, their own abilities and a sports-related value system, as well as being able to promote their health. We therefore hypothesise that parents might also be a protective factor in their adolescent children's doping susceptibility (DS). Even though previous research suggests including parents within educative prevention approaches, barely any research has evaluated the associations between parents and adolescents in terms of doping prevention. To our knowledge, only one study by Dodge ${ }^{[11]}$ evaluated effects of parental communication in terms of doping prevention, finding that parents who are not perceived as competent might fear an increase in anabolic steroid use if they discuss the topic with their children. However, there are many questions still outstanding on parents' involvement. 
The objective of this study was therefore to examine whether parents' knowledge, communication behaviour and beliefs on whether their child has the skills to become a professional athlete are associated with their DS. The results might provide an insight into whether parents have the potential to act as a protective factor in athletes' DS, which could possibly lead to new ideas for future preventive measures.

\section{Methods}

\section{Ethical considerations}

Prior to the collection of data this cross-sectional survey study was reviewed for protection of human subjects and approved by the research ethics committees of the Medical Universities of Innsbruck, Graz, Vienna and Lower Austria (Sankt Pölten) (Innsbruck: AN3854, 284/4.1., Graz: 23-206 ex 10/11, Vienna: 1096/2010, Sankt Pölten: GS4-EK-4/121-2011). The study is part of a research project evaluating knowledge and attitudes of Austrian junior elite athletes, their parents and trainers. All study participants were informed about the study goals and provided written informed consent. Based on Austrian law ( $\$ 21$ Allgemeines bürgerliches Gesetzbuch), adolescents aged 14 years and above are politically mature minors who were, in this specific situation, allowed to sign the written informed consent form on their own. The written consent forms from all participants were detached from the survey prior to analysis and kept in separate storage.

\section{Study design}

In total 12 of 27 recognised elite sport schools in Austria (selfrecruited) agreed to participate in the survey. In addition two training centres were included, based on personal invitation to take part in the study, as the best Tyrolean soccer and American football athletes matching the age criteria are training at these institutions.

Survey data were collected over a period of one year, between April, 2010 and April 2011, by distributing questionnaires to Austrian junior athletes aged between 14 and 19 years during class, these being directly collected by a member of the study team. Parents of these athletes also received a questionnaire and were asked to complete and return the forms either to the study site by the athlete and/or by mail using a stamped return envelope with the cost covered by the study budget. To ensure anonymity, data collection was performed with randomly encoded case report forms.

\section{Questionnaire structure}

A self-report questionnaire was developed based on previous published questionnaires used to evaluate doping knowledge ${ }^{[12]}$ and DS among athletes, ${ }^{[13]}$ and adapted for the parents in terms of wording. Subsequently the questionnaire was pretested on a sample of 20 athletes and their parents, and adapted based on the responses to the pre-test to avoid technical errors and misunderstandings.

As this study is part of a major research project, only those questions that refer to the current article's research hypotheses will be included in analyses. As well as sociodemographic data, situational information on amount of sport per week, kind of sport practised and previous PES offers were included, as they were shown to be associated with athletes' DS ${ }^{[14]}$ in previous studies. 'Kind of sport' was grouped into high-risk and low-risk sports. 'High-risk' sports included at least one of the following (athletes could indicate more than one sport): running, swimming, body-building, cross-country skiing, biathlon, biking, athletics and triathlon. In addition, the constructs outlined below were operationalised.

\section{Knowledge about effects of doping substances}

This section included 11 items with respect to possible effects of taking anabolic steroids, including side-effects affecting health (e.g. 'The use of anabolic steroids leads to an increase in muscle mass', true-false format) as used in a similar format in previous research. ${ }^{[12]}$ For data analysis a total score was computed. A score of 1 was achieved when all questions were answered correctly $(100 \%$ knowledge), whereas a score of 0 indicated no correct answer at all (0\% knowledge).

\section{Parental behaviour}

This construct included four items with respect to parental communication. One item questioned whether doping is a topic which is discussed by the parents with the physicians of their adolescent child (e.g. 'Do you discuss the issue "doping" with your child's physician?') and three items questioned whether general, physical and psychological problems are discussed with ( $i$ ) the trainer of their adolescent child, (ii) the physician of their adolescent child, and (iii) their adolescent child (binominal response scale - Yes/No) (Cronbach's alpha $=0.64$ ). For analysis a total mean construct score was computed $(0=$ No proactive communication, $4=$ Proactive communication).

\section{Parental beliefs}

This construct included three items with regard to whether parents believe their child has the skills to become a professional athlete and is mentally and physically strong enough to win ('Do you believe your child is mentally/physically strong enough to become a professional athlete?', 'Do you believe your child has the skills it takes to become a professional athlete?', using a five-point Likert-type rating scale from 'Very unsure' to 'Very sure'). The three items were combined to form an overall variable called 'Overall belief' by adding up a mean construct score $(0=$ No belief in their child having the skills to become a professional athlete, $12=$ Full belief in their child having the skills to become a professional athlete) (Cronbach's alpha $=0.8$ ).

\section{Doping susceptibility}

This construct was operationalised in presenting the athletes with four hypothetical situations followed by the question as to whether they would be willing to take a prohibited substance within these scenarios ('Your strongest opponent has doped and you know about it. Would you take a prohibited substance to increase your chances of winning?'; 'You have secure information that all your opponents have doped. Would you take a prohibited substance?'; 'If you could earn EUR1 million by winning a competition, would you take prohibited substances?'; and 'If there was no risk of getting caught while doping, would you take prohibited substances?') (Cronbach's alpha $=0.78$ ). To simplify data interpretation the nominal response scale ('Yes', 'No, 'Do not know') was aggregated to create binominal data (i.e. Yes/No). This practice can be found in previous doping research ${ }^{[15]}$ where reports show that anything other than a 'Definitely no/yes' response to future doping intentions indicates vulnerability. For data analyses a total mean construct score was computed $(0=$ Unsusceptible for doping, 4 = Highly susceptible for doping). 


\section{Statistical analysis}

Data were analysed using SPSS 20.0 (IBM, USA). The literature indicates that adolescent children may not view their mother's and father's influences similarly, ${ }^{[6,16]}$ and a previous study on parents' knowledge of and attitudes to doping found sex differences in doping knowledge, ${ }^{[17]}$ which is why data were analysed separately for mothers and fathers. We built a new variable to differentiate between households with both parents present, and only mother or only father present, as this might have an effect on athletes' DS. If a difference was found, data were analysed further separately.

Descriptive statistics were used, including mean (standard deviation (SD)). Non-parametric tests were applied since the data were not normally distributed ( $\left.p_{\mathrm{K}-\mathrm{s}}>0.05\right)$. The Mann-Whitney $U$-test was applied to test for differences in mothers' and fathers' knowledge about effects of doping substances, behaviour and belief scores. Preliminary Spearman correlation analyses were used to test the hypothesis of possible associations between parents' knowledge about effects of doping substances, behaviour and beliefs with athletes' DS.

Results are displayed with the corresponding correlation coefficient $r$ and the significance value $p$. Correlation analyses as well as previous literature findings were the basis for setting up a regression model of predicting factors for athletes' DS. Multicollinearity indices (variance inflation factor) $(1.02 ; 1.3)$ and graphical analyses of the dependent variable were verified and resulted in no severe violations of relevant prerequisites for applying linear multiple regression analyses. The two-sided significance level was defined as $p<0.05$.

\section{Results}

\section{Demographic data}

The survey was distributed to 1818 athletes, and 1673 completed questionnaires were returned (response rate 92\%). Parents returned 883 questionnaires, 409 completed by fathers and 474 by mothers. Calculation of a response rate is not possible here, since $87 \%$ of the parents had more than one child but filled out the questionnaire only once. Only those data sets which at least comprised one parent (mother or father) and his and/or her child were included. In total 527 data sets were entered in the final analysis: 308 included both parents, 79 included only the father, and 140 included only the mother.

The mean (SD) age of the mothers, fathers and athletes was 44.8 (4.3) , 47.3 (5.3) and 15.9 (1.4) years, respectively. Two-thirds (65.1\%) of the athletes were male and $34.5 \%$ were female; $0.4 \%$ did not indicate gender. For more detailed information on the parent and athlete samples, refer to Blank et al., ${ }^{[14,17]}$ respectively.

\section{Parents' knowledge about effects of doping substances, behaviour} and beliefs

Mothers' knowledge about effects of doping substances scored on average $0.72(0.2)$, whereas fathers' knowledge about effects of

Table 1. Associations between parents' KE, behaviour and beliefs, and athletes' DS

\begin{tabular}{|c|c|c|c|c|c|c|c|}
\hline & Athletes' DS & Mothers' KE & $\begin{array}{l}\text { Mothers' } \\
\text { behaviour }\end{array}$ & $\begin{array}{l}\text { Mothers' } \\
\text { beliefs }\end{array}$ & Fathers' KE & $\begin{array}{l}\text { Fathers' } \\
\text { behaviour }\end{array}$ & $\begin{array}{l}\text { Fathers' } \\
\text { beliefs }\end{array}$ \\
\hline \multicolumn{8}{|c|}{ Athletes' DS } \\
\hline$r$ & 1.00 & -0.10 & -0.01 & -0.03 & -0.07 & $-0.12^{\star}$ & $-0.20^{\dagger}$ \\
\hline$p$ & & 0.03 & 0.77 & 0.53 & 0.15 & 0.02 & $<0.001$ \\
\hline \multicolumn{8}{|c|}{ Mothers' KE } \\
\hline$r$ & & 1.00 & 0.11 & 0.11 & 0.25 & 0.08 & 0.07 \\
\hline$p$ & & & 0.02 & 0.02 & $<0.001$ & 0.34 & 0.22 \\
\hline \multicolumn{8}{|c|}{ Mothers' behaviour } \\
\hline$r$ & & & 1.00 & $0.19^{\dagger}$ & 0.03 & $0.29^{\dagger}$ & $0.17^{\ddagger}$ \\
\hline$p$ & & & & $<0.001$ & 0.54 & $<0.001$ & 0.002 \\
\hline \multicolumn{8}{|c|}{ Mothers' beliefs } \\
\hline$r$ & & & & 1.00 & -0.03 & $0.14^{*}$ & $0.29^{\dagger}$ \\
\hline$p$ & & & & & 0.59 & 0.012 & $<0.001$ \\
\hline \multicolumn{8}{|c|}{ Fathers' KE } \\
\hline$r$ & & & & & 1.00 & 0.07 & 0.01 \\
\hline$p$ & & & & & & 0.17 & 0.88 \\
\hline \multicolumn{8}{|c|}{ Fathers' behaviour } \\
\hline$r$ & & & & & & 1.00 & $0.26^{\dagger}$ \\
\hline$p$ & & & & & & & $<0.001$ \\
\hline \multicolumn{8}{|c|}{ Fathers' beliefs } \\
\hline$r$ & & & & & & & 1.00 \\
\hline $\begin{array}{l}\mathrm{KE}=\mathrm{knov} \\
{ }^{*} p<0.05 . \\
{ }^{+} p<0.001 . \\
{ }^{*} p<0.01 .\end{array}$ & loping substances. & & & & & & \\
\hline
\end{tabular}


doping substances scored 0.76 (0.2) ( $p=0.003)$. Parental behaviour and beliefs did not significantly differ between mothers and fathers (behaviour $_{\text {mothers }}=2.52(1.1) \mathrm{v}$. behaviour fathers $=2.41(1.2)$; beliefs $_{\text {mothers }}$ $=8.31(2.6) \mathrm{v}$. beliefs $\left.\mathrm{s}_{\text {fathers }}=8.6(2.6)\right)$. Associations between the variables are outlined in Table 1.

\section{Association with athletes' DS}

On average, athletes' DS score was 1.47 (1.5) (4 = highly susceptible), and it was significantly different in athletes who had received an offer of PES before and those who participated in high-risk sport $\left(\mathrm{DS}_{\text {high-risk sport }}=1.91(1.5) \mathrm{v} . \mathrm{DS}_{\text {low-risk sport }}=1.31\right.$ (1.4), $p<0.01 ; \mathrm{DS}_{\mathrm{PES}}$ offer $=2.24(1.5)$ v. $\left.\mathrm{DS}_{\text {no PES offer }}=1.36(1.4), p<0.001\right)$. No differences in gender and no associations with age or the hours of training per week of the athletes were found. Athletes' DS was also independent of the fact of having either both parents or only the mother or the father present. For associations of parental variables with athletes' DS, refer to Table 1.

\section{Multiple linear regression analysis}

Results of a first multiple linear regression analysis showed none of the parent-related variables to be a significant predictor. Whether both parents or a single mother or father were in the household did not alter the results. As interaction effects of fathers' behaviour and beliefs were assumed, an additional multiple regression analysis entering the prediction term of both was performed. In total the model explained $14.2 \%$ of the variance $(F=4.1, p<0.001)$. Predictive factors were kind of sport $(\beta=0.25, p=0.001)$ and fathers' belief $(\beta=-0.33, p=0.029)$. A tendency was found for fathers' behaviour to predict athletes' DS $(\beta=-0.44, p=0.054)$. Subsequent simple slope analyses to evaluate the interaction effect resulted in a significant negative predictive value for fathers' behaviour $(r=-0.26, p=0.042)$ only, if fathers' belief score ranged within the second tertile $(8 \leq$ score $\left._{\text {belief }}<10\right)$. In conditions with very low or very high expressions of fathers' belief, the fathers' behaviour was no significant predictor for athletes' DS.

\section{Discussion}

The main findings of the current study are that parental factors such as their knowledge about effects of doping substances, behaviour and beliefs explain only little of the variance in athletes' DS. Overall effect sizes are relatively low (between 0.1 and 0.3 ) and independent of the statistical significance, which might be due to the large sample size. One could therefore question the theoretical relevance. In fact, it seems that mothers in general play only a minor role in influencing athletes' DS. Subsequent regression analysis allows the conclusion that fathers' behaviour seems to be a protective factor against DS, but is moderated by their beliefs about their adolescent child's skills in terms of becoming a professional athlete. Nevertheless, most of the variance is explained by situational conditions such as kind of sport, and whether both parents are in the household or only the mother or father does not seem to play a role. Nevertheless, the last statement needs to be interpreted with caution, as the fact that questionnaires were filled in by only one parent, which provided the basis for these calculations, does not necessarily mean that the other parent is not also present in the household.
Parental behaviour and beliefs were not significantly different between mothers and fathers, yet scores were very moderate and provide room for improvement. Interestingly, behaviour variables showed significant associations, which implies that improving the one parent's behaviour also improves the other parents' behaviour. Only mothers' knowledge was positively associated with her behaviour. As observational studies do not allow for cause-effect relationships, one has to be careful not to overinterpret this result. On the one hand, it could be an indicator for the fact that mothers who discuss general and doping-related problems with trainers, physicians and their adolescent child also have an increased knowledge about doping. On the other hand, it could also mean that those who know more tend to communicate more about the issue. This finding would be in accordance with research by Blank et al. ${ }^{[4]}$ analysing coaches' behaviour.

Overall athletes' DS was low and comparable with results of previous research. ${ }^{[13]}$ In addition, DS was significantly higher in those athletes who had been offered PES before.

As previous research proposed that the beliefs of parents can influence the motivational climate for their children, resulting in poor or good sporting behaviour ${ }^{[6,16]}$ - which is linked to doping intention, ${ }^{[18]}$ we hypothesised associations between parental belief and athletes' DS. However, on first impression no parental variable had any predictive value for athletes' DS. Only after entering a prediction term of fathers' beliefs and behaviour were both these variables significant predictors of athletes' DS, with a much higher effect size. Obviously there is an interaction effect between fathers' beliefs and behaviours, and only fathers' and not mothers' beliefs and behaviour seem to play a role in predicting athletes' DS. Earlier research supports this finding, stating that fathers are the most important sport role model for adolescent children. ${ }^{[6,9]}$ Mothers' knowledge, which was associated with athletes' DS on a bivariate level, was no predicting factor for athletes' DS on regression analysis.

Generally the total variance experienced was very low (14.2\%). Even though fathers' behaviour, moderated by their beliefs, has some predictive value for athletes' DS, these outcomes seem to challenge findings from sports psychology, overall indicating a strong parental influence. ${ }^{[6,7,16]}$ This might be explained by the results of Chan et al., ${ }^{[19]}$ who argue that at the age of around 10 years parental influence fades and is replaced by the influence of peers. Participants in the current study were between 14 and 19 years old. Yet Steinberg ${ }^{[20]}$ states that parents generally remain the most influential of all relationships, and shape most of the important decisions confronting their children during adolescence.

Another explanation could be the different focus of the aforementioned studies, which was on the environmental climates of the athletes, especially in terms of motivation. Our findings do not necessarily indicate a strong association between knowledge and DS, which supports previous results that could not find any associations between athletes' knowledge about effects of doping substances and their doping behaviour and/or susceptibility. ${ }^{[21]}$ Nevertheless, in view of the research of Dodge, ${ }^{[11]}$ parents should still be included within educational prevention measures. Her study shows that parents discussing doping with their children and who are perceived as a non-credible source of information might have reason to fear an increase in anabolic steroid use. Hence, in 
the same way athletes' support personnel should be made aware of their role in influencing competitive climates, goal orientation and beliefs of success of the children, especially during adolescence. Given the results of this and previous studies, ${ }^{[6,9]}$ fathers should be a given a special focus.

\section{Study limitations}

This study has some limitations that need to be addressed. The questionnaire used in this study is self-reporting, possibly leading to socially desirable reporting. This may result in over- or underestimating findings. However, in a previous study by Barkoukis et al. ${ }^{[13]}$ effect sizes of socially desirable behaviour were actually rather small. Owing to the high multicollinearity of the interaction predictor, results in this regard need to be interpreted with caution, even though variance inflation factor values of the regression analyses indicated good values of fit. Lastly, owing to its cross-sectional and observational nature, the study results may not be interpreted causally. Correlation analyses only provide information on possible predictors of DS, but further research in the form of case-control studies is needed to define causes that allow for suggestions for future prevention strategies. In this regard social science research on doping is still in its infancy.

\section{Conclusion}

The objective of the study was to evaluate associations between parents' knowledge on effects of doping substances, behaviour and beliefs on athletes' DS. Interestingly, only fathers play a role in acting as a protective factor for athletes' DS. Yet this association interacts with the level of fathers' beliefs in the skills of their adolescent child to become a professional athlete. Overall the hypothesised variables explain only little of the variance in DS, and it can be assumed that parents have more of an effect on athletes' good and/or poor sport behaviour by affecting their environmental climate, as shown by sports psychology literature. We could also not find any significant influence as to whether both parents live in the same household or not. Nevertheless, future studies could integrate this exact question within the questionnaire, as we only hypothesised as to this by analysing whether questionnaires were filled in by both parents or only one of them.

Doping prevention strategies should include parents, but need to be careful as to the role which they are able to fulfil. Informing parents is necessary, as they need to be perceived as credible sources. Yet alone this seems insufficient, and the authors support previous claims of increased inclusion of soft skills, e.g. communication skills, in parentfocused prevention measures. Nevertheless, the study does not allow for proposing specific preventive measures, as additional research is needed to further determine parents' role in doping prevention and especially whether the focus should be directed to them or rather to athlete-centred measures, i.e. how to deal with parent-created climates efficiently.

As this was, to our knowledge, the first study of this kind, we urge the carrying out of further research on the parent-athlete link in terms of doping prevention. The variance explained in our study leaves some room for further investigation. Future research might include variables from sports psychology, such as motivational climate, goal orientation and belief of success, as possible mediators of the influence of parents on their adolescent children in the sports setting.

Acknowledgments. The authors would like to thank the Austrian Federal Ministry of Sport and Defence, the Government of Tyrol (Division of Sport), as well as the National Anti-Doping Agency, Vienna, Austria, for their support.

\section{References}

1. World Anti-Doping Agency. World Anti-Doping Code. Montreal: World-AntiDoping-Agency, 2009.

2. Laure P, Binsinger C. Doping prevalence among preadolescent athletes: A 4-year follow-up. Br J Sports Med 2007;41:660-663. [http//dx.doi.org/10.1136/ bjsm.2007.035733]

3. Goldberg L, Elliot D, MacKinnon DP, et al. Drug testing athletes to prevent substance abuse: Background and pilot study results of the SATURN (Student Athlete Testing Using Random Notification) Study. J Adolesc Health 2003;32:16-25. [http://dx.doi. org/10.1016/S1054-139X(02)00444-5]

4. Blank C, Leichtfried V, Fürhapter C, Müller D, Schobersberger W. Doping in sports: West-Austrian sport teachers' and coaches' knowledge, attitude and behavior. Dtsch Z Sportmed 2014;65(10):16-20. [http//dx.doi.org/ 10.5960/dzsm.2014.133]

5. Blank C, Müller D, Schobersberger W. Discrepancy between knowledge and interest of Austrian sports physicians with respect to doping and doping prevention in sports. Int Sports Med J 2014;15(2):136-145.

6. LaVoi NM, Babkes Stellino M. The relation between perceived parent-created sport climate and competitive male youth hockey players' good and poor sport behaviors. J Psychol 2008;142(5):471-495. [http//dx.doi.org/ 10.3200/JRLP.142.5.471-496]

7. White SA, Kavussanu M, Tank KM, Wingate JM. Perceived parental beliefs about the causes of success in sport: Relationship to athletes' achievement goals and personal beliefs. Scand J Med Sci Sports 2004;14:57-66. [http//dx.doi.org/10.1111/j.1600-0838.2003.00314.x]

8. Brustad RJ, Babkes ML, Smith AL. Youth in sport: Psychological considerations. In: Singer RN, Hausenblas HA, Janelle CM, eds. Handbook of research on sport psychology. New York: Wiley, 2001:604-635.

9. Greendorfer SL. Socializing processes and sport behavior. In: Horn T, ed. Advances in sport psychology. 2nd ed. Champaign: Human Kinetics, 2002:377-401.

10. Harris AL, Sutherland MA, Hutchinson MK. Parental influences of sexual risk among urban African American adolescent males. J Nurs Scholarsh 2013;45(2):141-150. [http//dx.doi.org/10.1111/jnu.12016]

11. Dodge T. Incorporating Parents in the Anti-Doping Fight: A Test of the Viability of a Parent-Based Prevention Program. Montreal: World Anti-Doping Agency, 2011.

12. Wanjek B, Rosendahl J, Strauss B, Gabriel HH. Doping, drugs and drug abuse among adolescents in the State of Thuringia (Germany): Prevalence, knowledge and attitudes. Int J Sports Med 2007;28(4):346-353. [http//dx.doi.org/ 10.1055/s-2006-924353]

13. Barkoukis V, Lazuras L, Tsorbatzoudis H. Beliefs about the causes of success in sports and susceptibility for doping use in adolescent athletes. J Sports Sci 2014;32(3):212219. [http//dx.doi.org/10.1080/02640414.2013.819521]

14. Blank C, Leichtfried V, Schaiter R, Müller D, Schobersberger W. Associations between doping knowledge, susceptibility and substance use of Austrian junior elite athletes. Jacobs J Sports Med 2014;1(1):1-8.

15. Gucciardi DF, Jalleh G, Donovan RJ. Does social desirability influence the relationship between doping attitudes and doping susceptibility in athletes? Psychol Sport Exerc 2010;11(6):479-486. [http//dx.doi.org/10.1016/j.psychsport.2010.06.002]

16. Appleton PR, Hall HK, Hill AP. Examining the influence of the parent-initiated and coach-created motivational climates upon athletes' perfectionistic cognitions. J Sports Sci 2011;29(7):661-671. [http//dx.doi.org/10.1080/02640414.2010.551541]

17. Blank C, Leichtfried V, Schaiter R, Furhapter C, Müller D, Schobersberger W. Doping in sports: Knowledge and attitudes among parents of Austrian junior athletes. Scand J Med Sci Sports 2015;25(1):1166-1124. [http//dx.doi.org/10.1111/sms.12168]

18. Barkoukis V, Lazuras L, Tsorbatzoudis H, Rodafinos A. Motivational and social cognitive predictors of doping intentions in elite sports: An integrated approach. Scand J Med Sci Sports 2013;23(5):330-340. [http//dx.doi.org/10.1111/sms.12068]

19. Chan DK, Lonsdale C, Fung HH. Influences of coaches, parents, and peers on the motivational patterns of child and adolescent athletes. Scand J Med Sci Sports 2012;22(4):558-568. [http//dx.doi.org/10.1111/j.1600-0838.2010.01277.x]

20. Steinberg L. We know some things: Parent-adolescent relationships in retrospect and prospect. J Res Adolesc 2001;11(1):1-19. [http//dx.doi.org/10.1111/1532-7795.00001]

21. Petroczi A. Attitude-behavior relationship regarding the use of performance enhancing drugs and/or methods. Med Sci Sports Exerc 2003;35(5):1. [http//dx.doi. org/00005768-200305001-01809] 